\title{
Estigmatização e Riscos no Trabalho dos Necrotomistas
}

\author{
Frankleudo Luan de Lima Silva ${ }^{1}$ \\ Paulo Cesar Zambroni de Souza \\ Anísio José da Silva Araújo \\ Universidade Federal da Paraíba \\ Francinaldo do Monte Pinto \\ Universidade Estadual da Paraíba
}

\begin{abstract}
RESUMO - Este artigo objetivou compreender de que maneira a estigmatização é vivenciada por necrotomistas e a relação que eles desenvolvem com os riscos de sua atividade. Quanto à teoria, utilizaram-se os conceitos de estigma e risco, articulando-os com elementos da Psicodinâmica do Trabalho. Metodologicamente, combinaram-se entrevistas semiestruturadas individuais e observações na sala de necropsias. Para a análise dos dados, a opção foi pela análise de conteúdo temática. Participaram deste estudo os necrotomistas do Departamento de Medicina Legal de uma capital do Nordeste brasileiro. Evidenciou-se que a intensa estigmatização está associada ao desconhecimento popular sobre sua atividade e à natureza de seu trabalho. A relação dos necrotomistas com os riscos, inclusive aqueles produzidos pela vivência do estigma, está mediada por um uso intensivo de estratégias defensivas que podem não contribuir para transformar positivamente as situações de trabalho.
\end{abstract}

Palavras-chave: estigma, segurança no trabalho, necrotomistas

\section{Stigmatization and Risks in the Work of Necrotomists}

\begin{abstract}
This article aimed to understand how stigma is experienced by necrotomists and the relationship they develop concerning risks of their activity. As regards to theory, we used the concepts of stigma and risk, linking them with elements of psychodynamics of work. Methodologically, individual semi-structured interviews and observations in the necropsy room were scheduled. For the data analysis, the option was for thematic content analysis. Necrotomists of the Department of Forensic Medicine of a Brazilian Northeastern city have participated in this study. Results indicated that: the intense stigmatization is associated with the popular ignorance about their activity and the nature of their work; the relationship of necrotomists with risks, including those produced by the experience of stigma, is mediated by an intensive use of defensive strategies that cannot contribute to positively transform work situations.
\end{abstract}

Keywords: stigma, occupational safety, necrotomists

Tendo por base a própria atividade e o que os trabalhadores sobre ela relatam, o presente artigo tem o duplo objetivo de, por um lado, compreender de que maneira a estigmatização é vivenciada por necrotomistas e, por outro, procurar entender o tipo de relação que esses trabalhadores desenvolvem com os riscos presentes em sua atividade. Os necrotomistas são servidores policiais que auxiliam peritos médico-legais e peritos odonto-legais na execução de necropsias médicolegais, realizadas em vítimas de mortes violentas ou de óbitos em circunstâncias suspeitas, para determinar a causa da morte, os meios empregados nesse evento e o tempo transcorrido entre o óbito e a necropsia, geralmente a fim de atender a solicitações judiciárias (Prestes Jr. \& Ancillotti, 2009; Salla \& Marinho, 2008).

Ressaltamos que foi o próprio processo de investigação do trabalho dos necrotomistas que alertou os pesquisadores que assinam este artigo quanto à necessidade de dedicar uma atenção particular à estigmatização sofrida por esses profissionais e aos riscos que envolvem sua atividade. Daí, nossa opção em discutir essas duas categorias no presente artigo, que é fruto da dissertação de mestrado do primeiro autor.

1 Endereço para correspondência: Rua Teresina, 96, Cruzeiro, Campina Grande, PB, Brasil. CEP: 58423-050.E-mail: keuleudao@hotmail.com

\section{Trabalho e Estigma}

De acordo com Barros e Silva (2004), nas investigações sobre o trabalho, há um aspecto que não tem sido suficientemente abordado, a saber, o caráter estigmatizante de determinadas atividades laborais. Citemos, a esse respeito, as atividades dos catadores de materiais recicláveis (Medeiros \& Macêdo, 2006), dos garis (Costa, 2008), dos trabalhadores de cemitérios, funerárias e similares (Dittmar, 1991), e dos agentes penitenciários (Lopes, 2002). Além de discriminadas por seu conteúdo, essas atividades submetem os trabalhadores a riscos diversos, ligados a condições insalubres e de sobrecarga física e psíquica (Barros \& Lhuilier, 2013).

Para descortinar esse aspecto insuficientemente investigado das atividades de trabalho, adotamos o sentido que Erving Goffman (1963/1998) conferiu à noção de estigma: uma diferenciação profundamente depreciativa, indesejada, que reduz ou macula o sujeito e que implica intolerância grupal. O sujeito estigmatizado surge não como uma individualidade empírica, mas como uma representação circunstancial aprisionada sob a fixidez do olhar do outro e ancorada em características diferenciadoras. Isso implica que o processo de estigmatização situa o indivíduo em uma condição de descrédito, de desvalor, de deteriorização identitária (Bacila, 2008; Martin, 1986; Goffman, 1963/1998). Segundo Link e Phelan (2001), as 
pessoas são estigmatizadas quando são rotuladas e ligadas a características indesejáveis, gerando uma experiência de discriminação e tornando-as, como argumenta Goffman, inabilitadas para a aceitação social plena.

Entendemos que a análise das atividades estigmatizadas pode ser iluminada pelo conceito de trabalho sujo (dirty work), proposto pelo sociólogo norte-americano Everett Hughes (1962). Para este, as tarefas que participam do universo do trabalho sujo são aquelas que remetem a uma experiência tabu, impura, indesejável. São ofícios que se ocupam de objetos física, moral ou socialmente degradantes e que, geralmente, sustentam indicadores de desprestígio social (Butler, Chillas, \& Muhr, 2012; Dick, 2005; Hughes, 1962; Mattos, 2012; Molinier, 2013). Todavia, a noção de sujo, como esclarece Hughes, não se refere a escuso, torpe ou ilegal. Ao contrário, o trabalho sujo refere-se a atividades necessárias que têm como objeto o que é usualmente mantido à distância e que, por isso, carregam marcas de uma construção social que lhes imprimiu características repulsivas, a ponto de o olhar do outro tender a identificar esse trabalhador ao objeto de seu trabalho (Ashforth \& Kreiner, 1999; Barros \& Lhuilier, 2013; Emerson \& Pollner, 1976; Hughes, 1962; Mattos, 2012; Roca, 2010; Wada \& Candela, 2010).

As atividades fisicamente sujas são aquelas que lidam com objetos literalmente sujos: lixo, esgoto, vísceras, cadáveres, dejetos, fluidos corporais. As atividades moralmente maculadas estão referidas aos ofícios, em geral, vistos como pecaminosos ou dúbios - profissionais do sexo, strippers - ou que desafiam normas de civilidade: guardas dos campos de concentração nazistas e investigadores privados (Ashforth \& Kreiner, 1999; Barros \& Silva, 2004; Dick, 2005; Hughes, 1962; Mattos, 2012). Já a mácula social dirige-se aos trabalhos que envolvem contato com públicos estigmatizados - como enfermeiras psiquiátricas, guardas prisionais e assistentes sociais - ou em circunstâncias de relações servis, como empregadas domésticas, garçons e engraxates (Ashforth \& Kreiner, 1999; Emerson \& Pollner, 1976; Hughes, 1962; Mattos, 2012).

Embora Hughes tenha tido a preocupação de distinguir esses diferentes tipos de atividades no espectro do trabalho sujo, há sempre o risco de confundi-las. Ainda mais porque as tipologias relativas ao trabalho sujo estabelecem critérios de análise, sendo sua identificação "uma questão de perspectiva e não empírica propriamente dita" (Mattos, 2012, p. 45). Dificilmente se pode resumir a realidade à ocorrência isolada de cada tipo de marca ou sujeira. Pelo contrário, a presença de mais de uma marca degradante é recorrente em certas atividades laborais (Dick, 2005).

Há também um aspecto que merece ser destacado no que tange às atividades abrangidas no conceito de trabalho sujo, qual seja: a sua desvalorização social. Esses trabalhadores estão colocados em uma situação que, além de apresentar as dificuldades próprias à atividade realizada, faz com que ocupem um lugar social de desvalia, o que não é sem consequência para eles, já que realizam um trabalho que não foi objeto de uma escolha (Dejours, 1983). Isso implica dizer que a população que realiza essas atividades o faz sob a pressão de uma condição social em que as chances de inserção em atividades que requerem qualificação formal, nobres e valorizadas socialmente são muito restritas. Em outros termos, a fatia atraente do mercado de trabalho é destinada à população que teve acesso, por exemplo, a um ensino diferenciado, nos seus vários níveis. Essa fatia desprezada do mercado de trabalho é o que resta para as pessoas que foram privadas de oportunidades que as permitissem aspirar a outra natureza de empregos (Mansur, 2012). Isso significa que temos aí, para além do que foi mencionado no que tange ao trabalho sujo - estigmatizado, cheio de riscos - uma condição social que por si procede à triagem da população para esse tipo de trabalho.

\section{Riscos no Trabalho}

No que se refere aos riscos, alguns autores afirmam seu caráter intrínseco a todas as atividades laborais, de modo que trabalhar implica sempre confrontar-se com eles (Dejours, 2012, 2015; Molinier, 2013; Nouroudine, 2004; Porto, 2000). Rouquayrol e Goldbaum (1999) definem o risco ocupacional como a probabilidade de um evento danoso à saúde ocorrer em um futuro imediato ou remoto. De forma assemelhada, a definição de risco proposta por Leplat (2003, como citado por Nouroudine, 2004, p. 39) situa-o como a "possibilidade de que um perigo se atualize, isto é, acarrete efetivamente danos, em condições determinadas". Porto (2000), por sua vez, assinala que fatores de risco à saúde decorrentes das condições de trabalho podem se apresentar de maneira isolada, entretanto seus efeitos se complexificam diante da interação de vários fatores: riscos biológicos, químicos, físicos, ergonômicos, psicológicos. A noção de carga de trabalho, por exemplo, está associada, em sua origem, a medição de fatores de risco isolados. Quando, entretanto, esses fatores encontram-se em interação (o que constitui efetivamente a realidade das situações de trabalho), a medição expõe os seus limites, o que torna difícil ou até impossível apreender o efeito combinado desses fatores de risco (Abrahão, Sznelwar, Silvino, Sarmet, \& Pinho, 2009). Embora as definições apresentadas associem risco à exposição a fatores deflagradores de agravos à saúde e à segurança, há um caráter fortemente subjetivo nos riscos (Dejours, 2004; Lancman \& Uchida, 2003; Nouroudine, 2004). Assim, além das ameaças concretas apresentadas pelas condições de trabalho, interessa saber também de que maneira os trabalhadores percebem os riscos, de que maneira os vivenciam em seu cotidiano (Dejours, 2011, 2012).

Um destaque particular deve ser dado aos riscos psicossociais, que adquiriram, nos últimos tempos, uma crescente importância em função do incremento de sua visibilidade (Costa \& Santos, 2013). As fontes de riscos psicossociais surgem da interação entre fatores relacionados à organização do trabalho, aos processos de gestão, ao desenho do trabalho, ao conteúdo e natureza do trabalho, às condições de trabalho, à relação entre vida profissional e extraprofissional, de um lado, e as capacidades, competências e necessidades dos trabalhadores, de outro. Tais interações podem gerar riscos para a saúde dos trabalhadores, ou seja, apresentam potencial para causar danos psicológicos, sociais ou físicos, em decorrência do modo como estes percebem e vivenciam tais fatores. De acordo com Gollac e Bodier (2011, como citado por Costa \& Santos, 2013), os 
fatores psicossociais de risco podem ser distribuídos em seis dimensões: "a intensidade do trabalho e o tempo de trabalho; as exigências emocionais; a falta/insuficiência de autonomia; a má qualidade das relações sociais de trabalho; os conflitos de valores e a insegurança na situação de trabalho/emprego" (p. 43). Esse conceito, objeto de uma exaustiva revisão feita por Costa e Santos (2013), pareceu-nos útil para refinar a compreensão da realidade dos necrotomistas, das interações dos aspectos organizacionais e do modo como percebem e vivenciam sua situação de trabalho.

Quando os homens trabalham, não estão somente produzindo, estão também se protegendo contra o sofrimento e os riscos presentes no trabalho, mediante elaboração de estratégias, principalmente coletivas, de defesa, conforme declara Dejours $(2011,2012)$. Essas estratégias hospedam sempre uma intenção, concertada pela coletividade, de alterar simbolicamente a posição subjetiva em relação aos riscos e garantir a continuidade do trabalhar. Dejours esclarece que as estratégias defensivas têm como alvo a percepção dos riscos que elas buscam abolir da consciência, podendo, desse modo, apresentarem-se conservacionistas, pois não contribuem para modificar, de fato, as situações potencialmente desestabilizadoras (Dejours, Abdoucheli, \& Jayet, 2011; Molinier, 2013). Por outro lado, a convivência com o risco e o perigo engendra determinados saberes, denominados por Cru e Dejours (1987) de saberes de prudência, que jogam um papel importante na segurança dos trabalhadores, embora no mais das vezes ignorado pelos órgãos responsáveis pela gestão da segurança no trabalho. Vemos, sob esse aspecto, um efeito positivo da convivência com o risco, que se expressa na constituição de um patrimônio comum de formas de enfrentamento do risco que podem ser acessadas a qualquer tempo por quem participa de determinado meio profissional.

\section{Método}

A presente pesquisa, de natureza qualitativa, foi realizada entre novembro de 2012 e março de 2013 no Departamento de Medicina Legal (DML) do Instituto de Polícia Científica (IPC) de uma capital do Nordeste brasileiro.

Participaram deste estudo os seis necrotomistas que compunham o quadro de profissionais do DML, sendo todos do sexo masculino, com idades variando de 32 a 48 anos, residentes na região metropolitana dessa capital e com tempo de serviço que se estendia de quatro a 23 anos. A condição de participar da pesquisa foi determinada pelo interesse de cada profissional, que, voluntariamente, registrou assinatura em um Termo de Consentimento Livre e Esclarecido. Enfatizamos que a participação de todos levou em consideração os aspectos éticos pertinentes à investigação envolvendo seres humanos, conforme resolução ( $n^{\circ}$ 466/2012) do Conselho Nacional de Saúde, e que este estudo foi submetido e aprovado por Comitê de Ética em Pesquisa.

Como estratégia de produção de dados, utilizamos um delineamento descritivo, valendo-nos de seis entrevistas semiestruturadas individuais e de quatro observações das atividades de trabalho dos necrotomistas.
A aceitação da gerência do DML para a efetivação da pesquisa ocorreu sem reticências ou obstáculos, exigindose tão somente apreciação e aval de um comitê de ética em pesquisa. Cumpridas as exigências burocráticas feitas pela gerência, foi autorizado o início dos procedimentos de coleta. Um dos membros do grupo de pesquisadores contactou, pessoalmente, no DML, cada necrotomista, para quem foi apresentada a proposta do estudo e feito o convite para a participação. Em vista da concordância, foram agendados dia e hora para as entrevistas individuais, que aconteceram na sede do DML, quase todas no período noturno, durante os plantões dos participantes. Com a anuência dos necrotomistas, as seis entrevistas foram gravadas e transcritas na íntegra. Ainda durante as entrevistas, foi solicitada a cada um deles a permissão para serem realizadas observações de suas atividades durante um expediente de trabalho.

As observações, que ocorreram após todos os participantes serem entrevistados, foram efetuadas na sala de necropsias, mediante autorização dos necrotomistas, da gerência do DML e dos peritos de plantão. Em datas distintas e com equipes distintas, realizamos quatro observações durante o expediente da manhã, de $8 \mathrm{~h}$ às $12 \mathrm{~h}$, quando, via de regra, o movimento na sala é mais intenso. Cada equipe plantonista é formada por dois peritos médico-legais, dois peritos odonto-legais e dois necrotomistas. Vale ressaltar que, apesar do trabalho ser realizado em equipe, o foco das observações incidiu na atividade dos necrotomistas, objetivando verificar a cronologia da atividade, ou seja, o modo como se combinavam ações, gestos, posturas adotadas, movimentações realizadas, comunicações (inclusive sob a forma de códigos), até mesmo os imprevistos enfrentados e as regulações que desencadearam.

A análise dos dados foi conduzida através da análise de conteúdo temática, na perspectiva proposta por Laville e Dionne (1999). Para esses autores, o princípio da análise de conteúdo consiste em desmontar a estrutura e os elementos do conteúdo obtido para esclarecer suas diferentes características e extrair sua significação, ou seja, compreender as significações no contexto da fala, fazendo inferências ao seu conteúdo. A definição das categorias analíticas pautou-se pelo modelo misto, com um elenco a priori de categorias extraídas dos referenciais teóricos adotados no estudo, porém com abertura para inclusão de categorias a posteriori oriundas do material empírico gerado pela pesquisa (Laville \& Dionne, 1999). A partir dos elementos produzidos no campo, foram construídas seis categorias de análise para a dissertação de mestrado que originou este artigo, sendo "estigma" e "riscos" aquelas que deram origem a este texto.

\section{Resultados e Discussões}

\section{"Criaram muitos mitos. De necrófilo a canibal. Tem de tudo": O processo de estigmatização do trabalho dos necrotomistas}

Diante da amplitude das atividades tipificadas como sujas na perspectiva apontada por Hughes (1962), damos ênfase nesta discussão ao trabalho sujo fisicamente repugnante, do 
qual o trabalho dos necrotomistas é exemplar. Para alguns profissionais que trabalham com cadáveres, lixo, dejetos, o contato com o objeto do trabalho é incontornável, ocupando esses objetos posição de inferioridade, de impureza, de infecção, de desprestígio e, até mesmo, de intocabilidade (Barros \& Lhuilier, 2013). De acordo com essas autoras, essas atividades, além de não possuírem uma imagem socialmente valorizada, estão susceptíveis de contaminar aqueles que as realizam. Fazer dos restos seu ofício não é tão simples: "significa confrontar-se com o que provoca nojo ou repulsa a si próprio e àqueles que possuem um olhar de desprezo sobre essas atividades ou desviam o olhar para manter o dejeto no esquecimento" (Barros \& Lhuilier, 2013, p. 672).

O processo de estigmatização que atravessa o trabalho dos necrotomistas parece se sustentar, fundamentalmente, em dois elementos: o contato com cadáveres humanos e o desconhecimento popular acerca de suas atividades. Quando falam de sua profissão para alguém, os necrotomistas percebem diferentes reações, como repugnância, estranhamento e curiosidade. A reação de repugnância está referida, decerto, ao objeto de trabalho - cadáveres em diversas fases de putrefação, corpos despedaçados, ossadas, despojos humanos -, o qual contamina as representações que se tramam em relação à atividade e aos profissionais que a desenvolvem (Rodrigues, 1983). A reação de estranhamento também foi identificada em pesquisa desenvolvida por Barros e Silva (2004) no IML da capital mineira. As autoras observam: "Aos olhos daqueles que desconhecem os procedimentos ali realizados - não só os procedimentos técnicos, como também a própria adaptação dos trabalhadores - parece ser uma tarefa insuportável"' (p. 329).

É como se o fato de trabalharem como necrotomistas os tornasse profissionais distintos, intrigantemente diferenciados. Ashforth e Kreiner (1999) caracterizam os trabalhadores que realizam trabalhos fisicamente sujos como aqueles para quem se dirigem perguntas do tipo "Como você pode fazer isso?" ("How can you do it?"). Nas entrevistas, esse tipo de situação foi mencionado, quando os necrotomistas relataram comentários desagradáveis que costumam ouvir: "Como é que você pode gostar disso?' Eles se referem à função como 'isso"” (Participante 1). "Podem me dar o dinheiro do mundo todo que eu não trabalharia nisso'. É como se esse trabalho não pudesse ser feito por um ser humano" (Participante 4). "Como é que tu tens coragem de abrir um 'cara'? Depois tu almoça? Tu dorme bem?" (Participante 5).

Também a curiosidade sobre os procedimentos, conforme revelaram as entrevistas, encontra-se entre as mais frequentes reações populares alusivas ao trabalho dos necrotomistas. Como argumentam Combinato e Queiroz (2006), o fenômeno da morte gera uma ambivalência de sentimentos: ao mesmo tempo em que nos atemoriza, perturba e causa mal-estar, produz em nós um efeito atrativo despertador de uma curiosidade mórbida sobre tudo o que lhe diz respeito. Os necrotomistas relataram que a curiosidade popular não se destina apenas aos procedimentos técnicos de seu trabalho, mas também a casos específicos de violência que obtêm repercussão midiática e que, muitas vezes, fazem parte de inquéritos policiais. Nessas situações, os necrotomistas, primando pelo sigilo e pela ética, preferem se desviar de perguntas indiscretas:
Eu procuro sair da conversa. Não porque eu tenha vergonha da minha profissão, mas porque as pessoas geralmente direcionam a conversa para algo específico: "Você estava lá naquele dia que mataram a menina tal?". A gente não pode dar detalhes, porque meu trabalho também envolve investigações policiais, envolve situações sigilosas. (Participante 6)

Quando expostos a determinadas situações sociais, esses profissionais evitam falar de seu trabalho e se identificar como necrotomistas. De acordo com Goffman (1963/1998) e Barros e Silva (2004), em algumas ocasiões, as invasões de privacidade - e sua consequente sensação desagradável - são intensificadas pela inconveniência de pessoas que, por uma curiosidade mórbida, sentem-se livres para iniciar conversas, como relatam:

Muitas vezes, eu estou numa farra, numa viagem, na praia, num ambiente que não tem nada a ver com meu trabalho, e lá vem o assunto de necropsia, de corpos. Então, eu evito falar do meu trabalho, eu tiro de tempo. Existe o espaço pra cada coisa... Muitas pessoas da minha cidade natal nem sabem que eu sou necrotomista. (Participante 1)

O desconhecimento, por parte da população em geral, das atividades realizadas no DML pesquisado produz uma série de representações equivocadas e pejorativas que repercutem negativamente na vida daqueles que lá trabalham. O estigma carregado pelo DML aos olhos da sociedade é diferente do estigma da Polícia, até porque as pessoas sequer associam uma instituição à outra (Mattos, 2012). A esse respeito, Aldé (2003) argumenta que não se conhece o IML porque não há interesse em se saber quase nada sobre essa instituição, em que se localiza o ponto final das expressões sociais violentas. Prossegue o autor: "Ninguém quer conhecer, de preferência ninguém quer passar nem perto do IML" (Aldé, 2003, p. 11). Para Rodrigues (1983), a identidade institucional do IML é contaminada pela natureza do trabalho lá desenvolvido, o qual estabelece uma íntima relação com a morte, tabu cultural difícil de romper.

Becker e Arnold (1986) observam que os indivíduos estigmatizados tornam-se rapidamente cientes da maneira como os outros os veem. Nesse sentido, os relatos dos necrotomistas nos fornecem exemplos de atitudes preconceituosas e degradantes que existem em relação ao seu trabalho:

"Tem gente que diz que a gente tira pedaços de vísceras pra fazer churrasco. Falam as coisas mais bizarras possiveis. Criaram muitos mitos. De necrófilo a canibal. Tem de tudo" (Participante 1).

A princípio, a gente ganha um monte de apelido, há um mito de que o necrotomista tem relações sexuais com os cadáveres femininos, de roubar peças humanas, de se admirar com os órgãos genitais (há um mistério nisso também), de ser imundo, de ser frio, de ser desumano, cachaceiro, viciado, doente. (Participante 2)

Barros e Silva (2004) parecem estar de acordo com Aldé (2003) quando endossam o argumento de que a estigmatização do trabalho e dos trabalhadores de IML é tributária, também, da ignorância, do desconhecimento. Os próprios necrotomistas, quando há oportunidade, buscam esclarecer as características de seu trabalho, como um antídoto para desconstruir os rótulos insultuosos ("necrófilos", "canibais", "porcos", “doentes", "sujos") 
que lhes são socialmente atribuídos e que constituem uma particular fonte de sofrimento. Um dos entrevistados declarou: "Eu procuro esclarecer, quando tenho uma oportunidade como esta, que é um trabalho responsável, que não existe, aqui, essas noções errôneas que as pessoas têm, entende? Trabalhamos com seriedade" (Participante 6).

\section{"O risco é grande, qualquer descuido pode comprometer nossa saúde": Riscos presentes nessa atividade}

Os necrotomistas reconhecem diversos riscos a que estão sujeitos. Quando questionados sobre os fatores de riscos que identificam em seu trabalho, todos os necrotomistas destacaram os riscos de contaminação por agentes biológicos. Principalmente durante as necropsias, esses profissionais se expõem ao contato inevitável com vírus, bactérias, fungos e outros micro-organismos com grande poder de transmissibilidade (Prestes Jr. \& Ancillotti, 2009). Assim, expôs um necrotomista: "Posso dizer pra você que o risco de doenças, de infecções nos acompanha o tempo todo. $O$ risco é grande, qualquer descuido pode comprometer nossa saúde" (Participante 3).

Nas entrevistas, os necrotomistas também identificaram a presença do que denominamos riscos ergonômicos: fatores que podem interferir nas características psicofisiológicas dos trabalhadores, causando desconforto ou afetando sua saúde, como levantamento de peso, ritmo excessivo de trabalho, posturas inadequadas que provocam alterações do sono, lesões osteomusculares e articulares etc. (Mendes, 2005). Observamos que, durante todo o expediente, os necrotomistas trabalham em pé, o que, segundo relataram, gera bastantes dores e cansaço nas pernas, costas, trapézios e cervical (já que inclinam o tronco para frente). Essa posição é corriqueira, pois contribui para uma maior precisão dos gestos e para a ampliação do campo de visão, seja relativo ao cadáver, seja referente à sala como um todo.

A colocação e retirada de cadáveres da mesa de necropsias, movimentos que exigem que os necrotomistas se agachem, podem ocasionar - e, em alguns, já se manifestaram - problemas posturais, como hérnias de disco e hérnias abdominais. Trata-se de problemas que se adquirem, via de regra, por acúmulo de esforço repetitivo (Mendes, 2005). Um dos necrotomistas declarou sofrer de insônia crônica. Ele acredita que o trabalho não foi a causa desse problema, mas o fato de assumir plantões de 24 horas parece agravar o quadro.

Eu tenho insônia crônica e até em casa isso se repercute. O que me incomoda é essa história de dormir e aqui a gente não dorme, porque, se chegar cadáver na madrugada, a gente tem que receber e colocar na sala. Então, o que mais me desgasta é isso. É um desgaste físico mesmo, porque você dorme mal e no outro dia você não consegue produzir, no outro dia você nem tá vivo nem tá morto. (Participante 5)

A esse respeito, autores comentam que sempre que a atividade laboral exigir trabalho em turnos, não importando que seja feito em turnos alternantes ou fixos, os trabalhadores estarão sujeitos a um descontrole do ciclo vigília-sono (Barthe, Gadbois, Prunier-Poulmaire, \& Quéinnec, 2004; Ferreira, 1985; Fischer \& Lieber, 2005; Seligmann-Silva, 2011)
Identificamos também os riscos de acidentes envolvendo os instrumentos perfurocortantes. Bisturis, facas de amputação, arcos de serra, tesouras, agulhas de sutura são instrumentos que podem facilmente romper as luvas de látex por eles utilizadas. Assim, o domínio das técnicas (Prestes Jr. \& Ancillotti, 2009), a destreza manual dos necrotomistas e a qualidade dessas ferramentas constituem elementos fundamentais para a prevenção de acidentes e para a eficiência das necropsias. Os acidentes durante as necropsias encerram dois agravantes: podem incapacitar permanentemente os profissionais para a prática das necropsias ("Já houve um caso, aqui, de um necrotomista que sofreu um corte e afetou o tendão do braço e perdeu a mobilidade para usar no diaa-dia" - Participante 4) e podem ocasionar infecções devido ao contato do instrumento com a corrente sanguínea desses profissionais (Prestes Jr. \& Ancillotti, 2009).

Para fazer frente aos riscos sempre presentes e aos constrangimentos engendrados pela organização do trabalho, os trabalhadores mobilizam defesas individual e coletivamente. São essas estratégias defensivas que, operando uma suavização da percepção da realidade que os faz sofrer, permitem aos trabalhadores resistirem às pressões do trabalho, amortizando-as e contribuindo para a manutenção do equilíbrio (dinâmico) psíquico (Dejours, 2011, 2012, 2015; Dejours et al., 2011). Chamaram-nos especial atenção os relatos de alguns necrotomistas que, por nunca terem se contaminado ao se acidentarem, passaram a eufemizar os riscos, ou a acreditar que são protegidos por Deus, ou que desenvolveram imunização devido à exposição constante a agentes infecciosos. Esse aspecto também foi enfatizado por Aldé (2003). Seja qual for a justificativa encontrada para o fato de tão poucos colegas ficarem doentes, essa constatação ajuda a conviver com os riscos.

"Felizmente, desde que eu entrei aqui, não há histórico de acidentes de trabalho que resultassem em enfermidades adquiridas. É como se algo nos protegesse. Não há nenhum histórico" (Participante 1).

Chegou o cadáver, ele pode ter AIDS, tuberculose, eu tenho que fazer a necropsia, a gente faz. Não tem nada que garanta a segurança para a gente. Se bem que a gente tem uma defesa imunológica muito alta. Graças a Deus, é difícil de a gente gripar ou contrair outras doenças corriqueiras. (Participante 5)

Destacamos, embora não tenha sido citada pelos necrotomistas, a presença de riscos de contaminação por agentes químicos em função do manuseio de substâncias como formol, álcool metílico e do contato com cianeto, chumbo, nitrato de prata, os quais podem estar presentes em certos fluidos corporais dos cadáveres. Sublinhamos ainda a eventual exposição a agentes radiológicos quando da manipulação de cadáveres contaminados por material radioativo. Nesse último caso, o risco de exposição tende a aumentar, pois a radiação ionizante não interage com nossos sentidos, de modo que ela não é percebida sem auxílio de instrumentos de monitorização de radioatividade (Prestes Jr. \& Ancillotti, 2009).

Dois necrotomistas se referiram, ainda, aos riscos psicossociais através das expressões "riscos interpessoais" ou "riscos de convivência", fazendo alusão, principalmente, às relações entre as categorias profissionais. Embora a maioria dos necrotomistas tenha classificado como "boas" essas 
relações, principalmente com os peritos, o aprofundamento da questão revelou a existência de problemas. Acreditamos que as "boas relações" não ocultam o fato de que existe uma hierarquia, cuja assimilação potencialmente tornaria as relações satisfatórias: "definidas as fronteiras que separam os profissionais e estabelecido o padrão de respeito a ser seguido nas equipes, bastaria cada um desempenhar seu papel que os conflitos não surgiriam" (Aldé, 2003, p. 118). Ou seja, não é a hierarquia ou a divisão do trabalho em si a fonte de problemas, mas as ultrapassagens, as hipersolicitações, $o$ desrespeito às fronteiras profissionais. É como se ao necrotomista fosse atribuída, por estar na base da pirâmide, a função de "faz tudo", assim como se representa o trabalhador doméstico, de quem se cobra polivalência, abnegação, dedicação sem limites, enfim, tudo aquilo que define a condição servil ("buscar as moças do interior"). Essa sim é a raiz dos conflitos. Num longo desabafo, um necrotomista se queixou das arbitrariedades e do desrespeito praticados por alguns peritos:

Quando precisamos fazer uma pausa, percebemos que os peritos não gostam, porque querem terminar logo seu serviço e ir embora. Tem peritos que nos veem apenas como instrumentos de trabalho. Pensam que a gente não sofre desgastes físicos. A gente já chegou a fazer 14 necropsias numa manhã. É difícil; tem deles que acham que somos empregadinhos, como se não tivéssemos entrado aqui por méritos próprios. É como se fossem aquelas famílias que mandam buscar as moças do interior para trabalharem pela metade do preço.

Os riscos psicossociais também foram referenciados como importantes pelos necrotomistas em seu dia a dia. A sobrecarga e a natureza do trabalho configuram, segundo os participantes, uma fonte se sofrimento que pode disparar algumas manifestações de irritabilidade no ambiente de trabalho, expandindo-se para a vida familiar.

Tem necrotomistas, aqui, que são mais estressados, mais hiperativos, em função, talvez, da natureza do trabalho, tem outros que são mais calmos. Muitas vezes, quando o dia é muito movimentado, o profissional que já tem predisposição à hiperatividade, no final do expediente, ele pode ficar agressivo com questões bobas. Devido à sobrecarga psíquica, eles podem "soltar os cachorros" por questões fúteis. (Participante 1)

Os riscos inerentes à atividade profissional se amplificam em decorrência das condições precárias de trabalho às quais estão submetidos. Por exemplo, observamos os necrotomistas utilizarem, em função da indisponibilidade de uma ferramenta adequada, uma faca sem cabo para talhar os ossos das bases cranianas dos cadáveres, à procura de projéteis ali alojados. Ainda que tal uso garanta a sequência dos procedimentos e o atendimento aos objetivos, com a redução significativa da área de contato entre a faca e a marreta, aumenta-se o risco de acidentes e acentua-se o desgaste físico. O participante 6 relatou:

Nós não temos equipamento nenhum para abrir as vértebras. Certa vez, eu fui numa loja de construção, comprei um martelo e comprei uma talhadeira, olha só! Por aí você tira a qualidade das condições técnicas. Esses que eu comprei também não são adequados, mas é uma adaptação, uma estratégia. Eu tenho que fazer isso, eu tenho que achar a bala. Hoje mesmo no meu plantão, tinha uma bala que entrou na região occipital e se alojou na base do crânio de um cadáver. Eu peguei um ferrinho para refazer a trajetória da bala, mas ele tinha que ir por baixo da base do crânio. Não tinha como fazer isso. Eu tive que pegar uma talhadeira e sair quebrando. Quando você termina a necropsia, você está morto de cansado e o cadáver desfigurado.

De acordo com Dejours (2012), os malefícios irredutíveis e inerentes à atividade de trabalho, além dos efeitos diretos produzidos no corpo, apresentam incidências indiretas sobre o funcionamento psíquico. Assim, entendemos que os necrotomistas estão expostos aos efeitos deletérios de lidarem cotidianamente com a morte, sobretudo a morte entrajada de violência. Corpos violentados, mutilados, putrefeitos, histórias tragicamente interrompidas são exemplos de situações desse cotidiano de trabalho frente às quais os necrotomistas mobilizam estratégias coletivas de defesa, a exemplo da coisificação dos cadáveres, isto é, tratá-los como objetos, destituídos de seus dramas e de suas histórias.

Se eu estou superconcentrado em identificar uma lesão ou mesmo, como falei, um projétil, eu desligo completamente de relacionar a pessoa com o corpo. Na verdade, é um dispositivo automático e eu acho que quem não fizer isso não vai se dar bem na profissão. (Participante 2)

Para esses profissionais, coisificar ou despersonalizar os cadáveres funciona como uma espécie de blindagem emocional que permite a esses trabalhadores continuarem a desenvolver suas atividades. "É uma questão de higiene mental, se você se compadecer com cada caso que seja, você não trabalha" (Participante 1). Não se trata, como fizeram questão de enfatizar, de uma mera frieza diante das dramáticas que se sucedem em sua atividade laboral, mas de um necessário recurso protetivo e adaptativo, catalisado nas relações intersubjetivas do trabalhar, capaz de evitar descompensações psicopatológicas.

A adesão à religião e o consumo de álcool, mesmo que esse consumo não seja tão pregnante como constatado em outras pesquisas (Halpern, Ferreira, \& Silva Filho, 2008; Lima, 2010; Rossato \& Kirchhof, 2004), parecem também configurar-se como mecanismos defensivos, para alguns necrotomistas, contra os aspectos deletérios do trabalho. Os depoimentos a seguir apontam nessa direção: "Eu sou católico, não sou praticante, mas faço minha oração quando chego, às $18 \mathrm{~h}$ rezo também e quando vou dormir, ou seja, eu tento me proteger religiosamente, porque é uma coisa que eu acredito" (Participante 4). "Mas eu acho que essa questão da bebida age como o bálsamo para o meu trabalho, um bálsamo meio perigoso. Funciona às vezes, funciona no dia, mas no dia seguinte a "deprê" vem dobrada" (Participante 5).

Não podemos deixar de sinalizar as formas de descontração - brincadeiras, piadas, utilização de apelidos, alguns cantarolaram durante as necropsias - como mais uma estratégia de defesa para os necrotomistas, buscando atenuar os efeitos dos constrangimentos presentes em sua atividade. "Tem que ter essas brincadeiras, senão a gente não aguenta isso aqui" (Participante 3). De acordo com Dejours (2012) e Barros e Silva (2004), essas práticas são comumente verificadas em situações de trabalho de aparente tetricidade, a fim de torná-las mais leves e suportáveis. No caso da atividade dos necrotomistas, as histórias são muitas 
e o detalhe que faz rir parece pequeno em meio à tragédia, mas, de toda a forma, parece distrair daquilo que machuca.

\section{Considerações Finais}

No presente estudo, evidenciamos que a análise da atividade dos necrotomistas sugere que a natureza do trabalho - que faz referência à morte e desperta estranheza, repugnância e curiosidade alheias - e o desconhecimento das atividades por eles realizadas precipitam a estigmatização, colocada como trabalho sujo e fonte considerável de sofrimento. Em um segundo plano, identificamos que a relação dos necrotomistas com os diversos riscos está mediada por estratégias defensivas individuais e coletivas, sem as quais a vivência do sofrimento e do medo se faria muito mais sentida. Essas estratégias de defesa são psiquicamente equilibrantes e objetivamente conservacionistas, isto é, facultam aos necrotomistas o enfrentamento e a eufemização das situações de trabalho, mas não favorecem a transformação da realidade de trabalho, contribuindo para a preservação dos riscos. $\mathrm{O}$ recurso à defesa é o caminho natural de quem se vê diante do risco e do perigo e cumpre, se utilizada com parcimônia, uma função protetiva no tocante à saúde mental. Não obstante, quando utilizada em excesso, pode favorecer certa acomodação, uma naturalização do risco, transformando aquilo que deve gerar indignação e converter-se em objeto de luta em algo familiar, em elemento do cotidiano, uma fatalidade inescapável. Os resultados indicam a necessidade de se desenvolver uma agenda de pesquisa que considere a realização, em outros departamentos de medicina legal, de estudos futuros que ampliem a compreensão da dinâmica organizacional, das representações e das relações profissionais envolvidas no trabalho dos necrotomistas.

Ressaltamos que esta pesquisa pretende apresentar uma contribuição de caráter social, uma vez que descortina o trabalho desenvolvido pelos necrotomistas que participam de cadeias investigativo-judiciárias. Trata-se, assim, de profissionais que figuram como centrais em todo o processo de necropsia, apesar de invisíveis no laudo final. Entendemos que as reflexões e conclusões deste estudo nos remetem à urgência de trazer para a agenda pública uma discussão institucional sobre o papel dos necrotomistas, muitas vezes rechaçados e esquecidos, trabalhando com importantes riscos à sua saúde, objetivando-se garantir-lhes visibilidade social, reconhecer sua importância e desconstruir os muitos estigmas conferidos a essa categoria profissional.

Se, no caso dos necrotomistas, por um lado, estigmas e riscos aparecem imbricados, por outro, esses profissionais conseguem construir uma relação com sua profissão em que aparece o respeito a si, à sua atividade e, em especial, ao seu objeto de trabalho, a saber, os cadáveres que ali se apresentam. Parece haver ainda um longo percurso para que tenham maior reconhecimento social, capaz de dar maior visibilidade e valorização a seu trabalho. A melhora nesse quadro poderia contribuir para a própria redução dos estigmas que sofrem e para a mudança positiva das suas condições de trabalho com consequente redução dos riscos, já que quem está invisível aos olhos da sociedade acaba sendo colocado para se submeter aos riscos mais diversos, justamente por permanecer invisível.

Entendemos que tais melhorias favoreceriam não apenas aos necrotomistas, mas à sociedade em geral, pois acreditamos que, quando grupos sociais melhoram suas vidas, essa transformação se reflete na melhoria da vida de todos. Esse parece ser o exemplo deixado na luta contra o racismo, a homofobia, o machismo e todas as manifestações discriminatórias que a humanidade insiste em criar.

\section{Referências}

Abrahão, J., Sznelwar, L., Silvino, A., Sarmet, M., \& Pinho, D. (2009). Introdução à ergonomia: Da prática à teoria. São Paulo: Blucher.

Aldé, L. (2003). Ossos do oficio: processo de trabalho saúde sob a ótica dos funcionários do Instituto Médico-Legal do Rio de Janeiro (Unpublished master's thesis). Fundação Oswaldo Cruz, Rio de Janeiro. Recuperado em 12 de março de 2012, de http://teses.icict.fiocruz.br/pdf/aldelm.pdf.

Ashforth, B. E., \& Kreiner, G. E. (1999). "How Can You Do It?": Dirty Work and the Challenge of Constructing a Positive Identity. The Academy of Management Review, 24(3), 413434. Recuperado em 16 de abril. 2013, de: http://www.jstor. org $/$ discover $/ 10.2307 / 259134$ ?uid=3737664\&uid=2\&uid=4\& sid $=21102142762513$.

Bacila, C. R. (2008). Estigmas: Escritos a partir de duas obras inacabadas sobre preconceitos. Novos Estudos Jurídicos, 13(2), 61-75. Recuperado em 08 de setembro, 2013, de http:// siaiweb06.univali.br/seer/index/article/view/1440/1143.

Barros, V. A., \& Silva, L. R. (2004). Trabalho e cotidiano no Instituto Médico Legal de Belo Horizonte. Psicologia em Revista, 10(16), 318-333.

Barros, V. A., \& Lhuilier, D. (2013). Marginalidade e reintegração social: O trabalho nas prisões. Manuscrito não publicado.

Barthe, B., Gadbois, C., Prunier-Poulmaire, S., \& Quéinnec, Y. (2004). Trabalhar em horários atípicos. In P. Falzon (Ed.), Ergonomia (G. M. J. Ingratta, M. Maffei, M. W. R. Snelwar, M. A. Oliveira, \& A. N. Puntch, trads., pp. 97-109). São Paulo: Editora Blucher.

Becker, G., \& Arnold, R. (1986). Stigma as a social and culture construct. In S. C. Ainlay, G. Becker, \& L. M. A. Colman. (Eds.), The Dilemma of Difference (pp. 39-76). New York: Plenum.

Butler, N., Chillas, S., \& Muhr, S. L. (2012). Professions at the margins. Ephemera: Theory \& politics in organization. 12(3), 259-272. Recuperado em 19 de agosto, 2013, de http://www. ephemerajournal.org/sites/default/files/12-3editorial.pdf

Combinato, D. S., \& Queiroz, M. S. (2006). Morte: uma visão psicossocial. Estudos de Psicologia (Natal), 11(2), 209-216.

Costa, L. S., \& Santos, M. (2013). Fatores psicossociais de risco no trabalho: Lições aprendidas e novos caminhos. International Journal on Working Conditions, 5, 39-58.

Costa, F. B. (2008). Moisés e Nilce: retratos biográficos de dois garis. Um estudo de psicologia social a partir de observação participante e entrevistas (Unpublished doctoral dissertation). Instituto de Psicologia, Universidade de São Paulo, São Paulo. Recuperado em 04 de maio, 2013, de: http://www.teses.usp.br/ teses/disponiveis/47/47134/.../costafernando_do.pd. 
Cru, D., \& Dejours, C. (1987). Saberes de prudência nas profissões da construção civil: Nova contribuição da Psicologia do Trabalho à análise da prevenção de acidentes na Construção Civil. Revista Brasileira de Saúde Ocupacional, 15(59), 30-34.

Dejours, C. (1983). Réactions psychopathologiques aux ruptures involontaires d'activité professionnelle (retraite, licenciement, maladie, reclassement). Psychologie médicale, 15(11), 18751880 .

Dejours, C. (2004). Subjetividade, trabalho e ação. Revista Produção, 14(3), 27-34.

Dejours, C. (2011). Uma resposta durante o seminário "Sofrimento e prazer no trabalho”. In. S. Lancman, \& L. I. Sznelwar (Orgs.). Christophe Dejours: Da psicopatologia à psicodinâmica do trabalho (3 ${ }^{\mathrm{a}}$ ed., F. Soudant, trad., pp. 185-192). Brasília: Paralelo 15.

Dejours, C. (2012). Trabalho vivo (F. Soudant, trad.). Brasília: Paralelo 15.

Dejours, C. (2015). Le choix, Souffrir au travail n'est pas une fatalité. Paris: Bayard.

Dejours, C., Abdoucheli, E., \& Jayet, C. (2011). Psicodinâmica do trabalho: Contribuições da escola dejouriana à análise da relação prazer, sofrimento e trabalho (M. I. S. Betiol, coord. e trad). São Paulo: Atlas.

Dick, P. (2005) "Dirty work designations: How police officers account for their use of coercive force". Human Relations, 58(11): 1363-1390. Recuperado em 19, agosto de 2013, de http://hum.sagepub.com/content/58/11/1363.full.pdf+html

Dittmar, W. H. (1991). Um estudo sobre a prevalência de distúrbios psiquiátricos entre sepultadores do serviço funerário do município de São Paulo (Unpublished master's thesis). Faculdade de Medicina, Universidade de São Paulo, São Paulo.

Emerson, R. M., \& Pollner, M. (1976). Dirty work designations: Their features and consequences in a psychiatric setting. Social Problems, 23(3), 243-254. Recuperado em 16 de abril, 2013, de http://www.jstor.org/discover/10.2307/799771?uid=37376 64\&uid=2\&uid=4\&sid=21102142762513.

Ferreira, L. L. (1985). Sono dos trabalhadores em turnos alternantes. Revista Brasileira de Saúde Ocupacional., 13(51), 25-27.

Fischer, F. M., \& Lieber, R. R. (2005). Trabalho em turnos. In R. Mendes (Org.), Psicologia do trabalho (2 ed., pp. 825-868). São Paulo: Ed. Ateneu.

Goffman, E. (1998). Estigma: Notas de uma identidade deteriorada (4a ed.). Rio de Janeiro: LTC. (Obra original publicada em 1963)

Halpern, E. E., Ferreira, S. M. B., \& Silva Filho, J. F. (2008). Os efeitos das situações de trabalho na construção do alcoolismo de pacientes militares da marinha do Brasil. Cadernos de Psicologia Social do Trabalho, 11(2), 273-286.

Hughes, E. C. (1962). Good people and dirty work. Social Problems, 10(1), 3-11. Recuperado em 03 de junho, 2013, de http://www. jstor.org/discover/10.2307/799402?uid=3737664\&uid=2\&uid $=4 \&$ sid $=21102142762513$.

Lancman, S., \& Uchida, S. (2003). Trabalho e subjetividade: O olhar da psicodinâmica do trabalho. Cadernos de Psicologia Social do Trabalho, 6(1), 79-90.

Laville, C., \& Dionne, J. (1999). A construção do saber: manual de metodologia da pesquisa em ciências humanas. Porto Alegre: Ed. UFMG/ArtMed.
Lima, M. E. A. (2010). Dependência química e trabalho: Uso funcional e disfuncional de drogas nos contextos laborais. Revista Brasileira de Saúde Ocupacional, 35(122), 260-268.

Link, B. G., \& Phelan, J. C. (2001). Conceptualizing stigma. Annual Review of Sociology, New York, 1(27), 363-385. Recuperado em 05 de setembro, 2013, de http://arjournals.annualreviews.org/.

Lopes, R. (2002). O cotidiano da violência: O trabalho do agente de segurança penitenciária nas instituições prisionais. Psicología para América Latina, 1(0), 15-22. Recuperado em 20 de maio de 2015, de http://www.ulapsi.org/portal/arquivos/revistas/ Numero-0.pdf

Mansur, F. (2012). As ocupações precárias e o desemprego disfarçado. Revista do Instituto Humanitas Unisinos on-line, 12(390). Recuperado em 22 de abril de 2015, de http://www. ihuonline.unisinos.br/index.php?option $=$ com_con tent\&view $=$ article $\& i d=4387 \&$ secao $=390$.

Martin, L. G. (1986). Stigma: A social learning perspective. In S. C. Ainlay, G. C. Becker, \& L. M. A. Colman. (Eds.), The Dilemma of Difference (pp.145-161). New York: Plenum.

Mattos, M. J. S. (2012). Reconhecimento, identidade e trabalho sujo na PMDF (Unpublished master's thesis). Departamento de Sociologia, Universidade de Brasília, Brasília. Recuperado em 06 de setembro, 2013, de http://repositorio.unb.br/bitstrea m/10482/111/2012MarcioJuliodaSilvaMattos.pdf

Medeiros, L. F. R., \& Macêdo, K. B. (2006). Catador de material reciclável: Uma profissão para além da sobrevivência? Psicologia \& Sociedade, 18(2), 62-71.

Mendes, R. (2005). Psicologia do trabalho (2 ed.). São Paulo: Ed. Ateneu.

Molinier, P. (2013). Trabalho e psique: Uma introdução à psicodinâmica do trabalho (F. Soudant, trans.). Brasília: Paralelo 15.

Nouroddine, A. (2004). Risco e atividade humana: Acerca da possível positividade aí presente. In M. Figueiredo, M. Athayde, J. Brito, \& D. Alvarez (Orgs.), Labirintos do trabalho: Interrogações e olhares sobre o trabalho vivo (pp. 37-62). Rio de Janeiro: DP\&A.

Porto, M. F. P. (2000). Análise de riscos nos locais de trabalho: Conhecer para transformar. Cadernos de saude do trabalhador (pp. 5-41). São Paulo: Instituto Nacional de Saúde do Trabalhador..

Prestes Jr, L. C., \& Ancilotti, R. (2009). Manual de técnicas em necropsia médico-legal. Rio de Janeiro: Editora Rubio.

Roca, E. (2010). The exercise of moral imagination in stigmatized work groups. Journal of Business Ethics, 96, 135-147. Recuperado em 20 de novembro, 2013, de http://earchivo. uc3m.es/bitstream/handle/10016/13326/exercise_roca_ JOBE_2010

Rodrigues, J. C. (1983). Tabu da morte. Rio de Janeiro: Achiamé.

Rossato, V. M. D., \& Kirchhof, A. L. C. (2004). O trabalho e o alcoolismo: Estudo com trabalhadores. Revista Brasileira de Enfermagem, 57(3), 344-349.

Rouquayrol, M. Z., \& Goldbaum, M. (1999). Epidemiologia, história natural e prevenção de doenças (5 ed). Rio de Janeiro: MEDSI. 
Salla, F., \& Marinho, M. G. S. M. C. (2008, Setembro). Medicina legal e perícias médicas em processos criminais. [CD-ROM]. In Anais do XIX Encontro Regional de História: Poder, Violência e Exclusão. São Paulo: Universidade de São Paulo. Recuperado em 30 de agosto, 2013, de: http://www.anpuhsp. org.br/sp/downloads/CD\%20XIX/PDF/Autores\%20.

Seligmann-Silva, E. (2011). Trabalho e desgaste mental: $O$ direito de ser dono de si mesmo. São Paulo: Cortez.
Seligmann-Silva, E. (2006, Outubro). Psicopatologia no trabalho: aspectos contemporâneos. In Anais do II Congresso Internacional sobre saúde mental no trabalho (pp.64-98). Goiania: CIR.

Wada, J. C. R. P., \& Candela, K. (2010). Betwixt and between: The perceived legitimacy of campus police. Policing: An International Journal of Police Strategies \& Management, $33(1), 114-131$.

Recebido em 20.12.2013

Primeira decisão editorial em 01.04.2015

Versão final em 24.04.2015

Aceito em 20.05.2015 